\title{
Design and Analysis of Microstrip Patch Antenna for Different Applications
}

\author{
Snehal D. Tingane ${ }^{1}$, P. N. Pusdekar ${ }^{2}$ \\ ${ }^{1}$ PG Scholar, Dept. of EXTC, P R Pote College of Engineering \& Management, Amravati, Maharashtra, India \\ ${ }^{2}$ Assistant Professor, Dept. of EXTC, P R Pote College of Engineering \& Management, Amravati, Maharashtra
}

\begin{abstract}
As Microstrip Patch antenna (MPA) is low profile, less costly and low volume, it is used now a day for different applications. Microstrip Patch antenna is targeted for improving its performance based on various factors. A printed antenna can be used in wireless communication at different operating frequencies. In this speedy dynamic world of wireless communication, dual or multiband antenna has been playing a key role for wireless service applications. This paper demonstrate, the performance analysis of microstrip antenna for various parameters such as Return loss, VSWR and radiation pattern. Results are simulated on different antenna geometries. The analysis of antenna for physical parameters such as area of substrate, height of substrate, patch shape and dielectric constant of substrate been done by varying one of them and achieving improve result of performance.
\end{abstract}

Keywords: MPA, VSWR, Return Loss, Substrate, HFSS, VNA

\section{Introduction}

A microstrip patch antenna (MPA) is commonly used because it is lightweight, low profile and simple structure antennas with reliability, mobility and good efficiency [1]. The design of a microstrip antenna initiates by deciding used for the antenna so the size of the patch. There are many types of shapes in patch antenna. Circular, Rectangular and Square shapes are the traditional shapes. But elliptical, triangular, dipole, ring are also uses for patch antenna.

The performance of a patch antenna depend not only on the shape of antenna but dielectric constant of the substrate, dimensions of the dielectric substrate and ground also affects the performance of the patch antenna. It may be possible that all shapes gives different performance on different frequencies.

The most commonly employed micro strip patch antenna is a rectangular patch [6]. The rectangular patch antenna is approximately a one wavelength long section of rectangular microstrip transmission line.

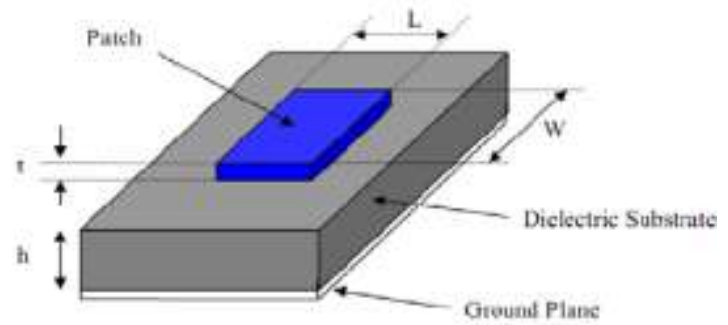

Figure 1: Structure of Microstrip patch Antenna

In above figure parameters are as follows.

Here, $\mathrm{t}=$ thickness of patch

$\mathrm{h}=$ height of dielectric substrate

$\mathrm{L}=$ length of patch

$\mathrm{W}=$ width of patch

Patch antenna consist of following:

Patch (perfect electric conductor)

Substrate

Ground (perfect electric conductor)

\section{System Analysis}

Generally, a patch of the microstrip antenna is made from the radiating material. It is of conducting material such as copper or gold. The patch can be of any shape like circular, triangular, rectangular [4] and even alphabets like $\mathrm{H}, \mathrm{U}, \mathrm{E}$, $\mathrm{C}, \mathrm{F}$ etc.

Performance of microstrip patch antenna is based on the various parameters such as VSWR, Return loss, impedance Bandwidth and radiation pattern etc along with physical parameters such as width, height, length and design of patch, and length, height, width of substrate. So it becomes crucial to design appropriate microstrip patch antenna with improved VSWR \& return for various application.

The patch of microstrip antenna for various shapes was design earlier and the result associated with it is calculated with respect to VSWR and Return loss. The table given below demonstrates the result for various shape of patch as follows.

Table 1: VSWR \& Return loss for various shapes

\begin{tabular}{|c|c|c|}
\hline Type of shape & VSWR & Return loss in dB \\
\hline H & 1.33 & -16.34 \\
\hline I & 1.37 & -15.94 \\
\hline Star & 1.43 & -16.98 \\
\hline Mho & $<2$ & -15.83 \\
\hline V & 1.08 & -28 \\
\hline E & 1.031 & -34 \\
\hline
\end{tabular}

\subsection{Estimation of parameter}

Step 1: Calculation of the width of Patch $(W)$-The width of the Micro strip patch antenna is given as

For $f_{0}=2.4 \mathrm{GHz}, s_{r}=4.4$

$$
\mathrm{W}=\frac{c}{2 f_{0} \sqrt{\frac{s_{r}+1}{2}}}
$$

Step 2: Calculation of effective dielectric constant: Fringing makes the micro strip line look wider electrically

Volume 6 Issue 12, December 2017 www.ijsr.net 


\section{International Journal of Science and Research (IJSR) \\ ISSN (Online): 2319-7064}

Index Copernicus Value (2016): 79.57 | Impact Factor (2015): 6.391

compared to its physical dimensions. Since some of the waves travel in the substrate and some in air, an effective dielectric constant is introduced, given as:

$$
\varepsilon_{r e f f}=\frac{\varepsilon_{r}+1}{2}+\frac{\varepsilon_{r}-1}{2}\left[1+12 \frac{h}{W}\right]^{-\frac{1}{2}}
$$

Step 3: Calculation of Length of Patch $(\mathbf{L})$-The effective length due to fringing is given as:

$$
L_{e f f}=\frac{c}{2 f_{0} \sqrt{\varepsilon_{r e f f}}}
$$

Substituting $\varepsilon_{\text {reff }}=4.4, \mathrm{c}=3.00 \mathrm{e}+008 \mathrm{~m} / \mathrm{s}$ and $\quad f_{0}=2$ $\mathrm{GH}$

Step 4: Calculation of $\Delta \mathbf{L}$ - Due to fringing the dimension of the patch as increased by $\Delta \mathrm{L}$ on both the sides, given by:

$$
\Delta L=0.412 h \frac{\left(\varepsilon_{\text {reff }}+0.3\right)\left(\frac{W}{h}+0.264\right)}{\left(\varepsilon_{\text {reff }}-0.258\right)\left(\frac{W}{h}+0.8\right)}
$$

Step 5: Calculation of Substrate dimension-

For this design this substrate dimension would be

$$
L_{S}=L+2 * 6 h
$$

\section{Step 6: Calculation of VSWR}

$$
V S W R=\frac{1+\tau}{1-\tau}
$$

Step 7: Calculation of Return loss

$$
R L=10 \log _{10}(\tau) d B
$$

\subsection{Structural flow}

Work is started with analysis of various approaches for microstrip patch antenna [3]. At the beginning simple patch is designed using the parameters given below. After this length and width of patch is specified with help of mathematical formulas explained in the above section. Once E shape antenna is designed, simulation has been done on it with help of standard tools to calculate VSWR and Return Loss. Finally on the basis of optimized results fabrication is done.

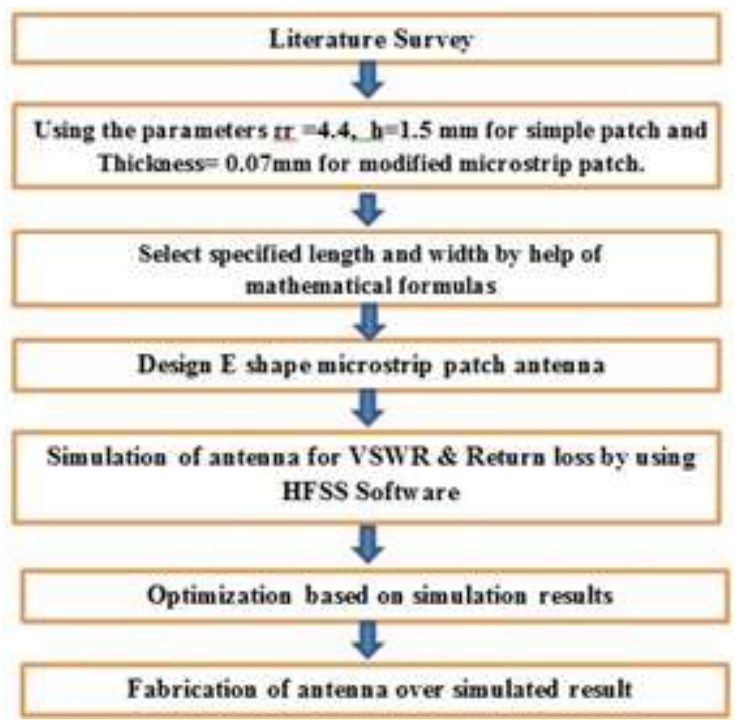

\section{Design and Fabrication of Antenna}

The design of the E shaped patch antenna is shown in figure 2. The Defined double E- shape microstrip patch antenna having single edge rectangular slot cut at middle portion of it. This antenna is design using wave port feed technique. We have changed the width, length and height of substrate and thickness and shape of the patch.

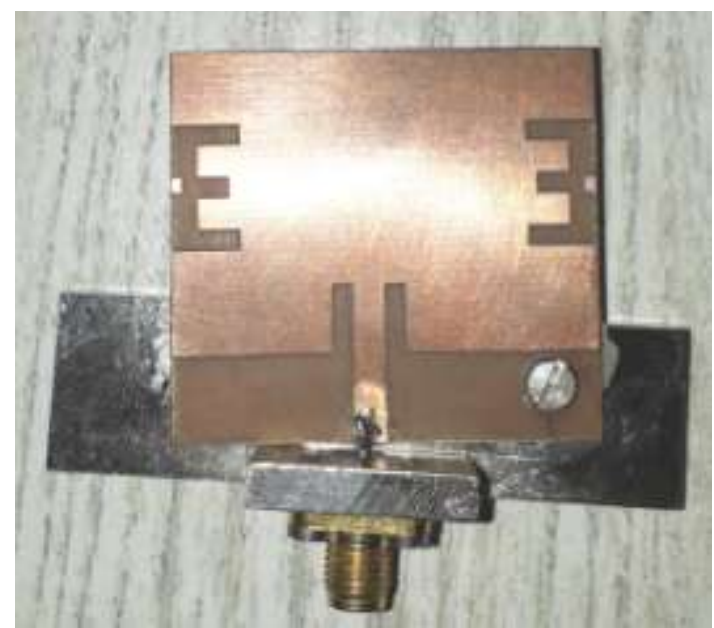

Figure 2: Double E shape Antenna

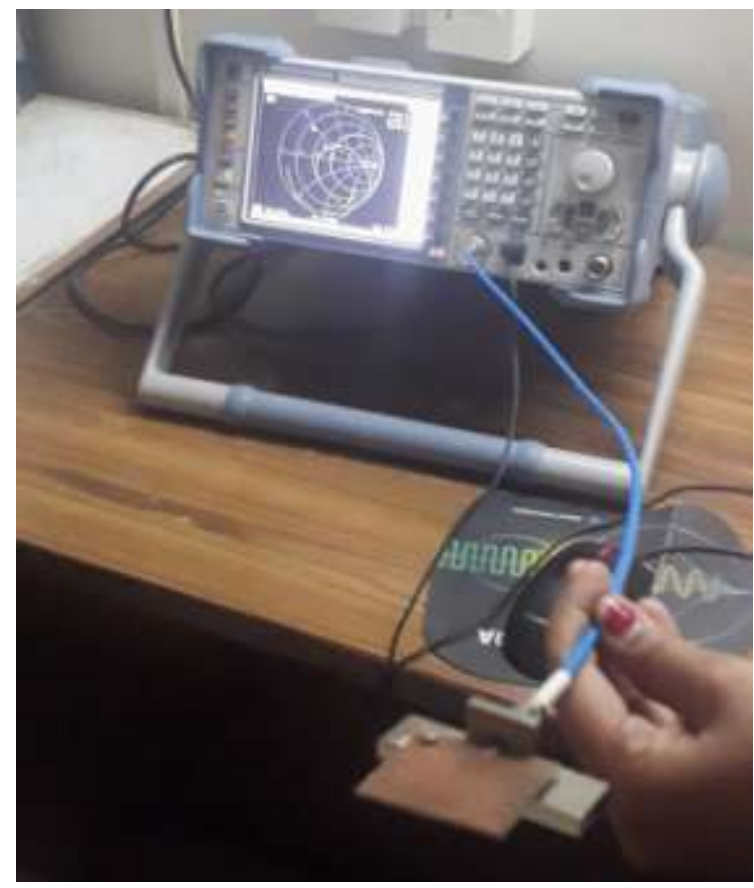

Figure 3: Testing of fabricated antenna

Rectangular microstrip patch antenna has a compact dimension of $40.00 \mathrm{~mm} \times 28.85 \mathrm{~mm}$ (Width $\times$ Length), designed on FR4 substrate with thickness of $1.5 \mathrm{~mm}$ and dielectric constant (cr) of 4.4. The antenna is fed by a microstrip line of $3.00 \mathrm{~mm}$ cut width and $7.00 \mathrm{~mm}$ cut depth. The probe is used $50 \Omega$ microstrip line printed on the partial grounded substrate with resonance frequency of $2.42 \mathrm{GHz}$. The results are obtained by using vector network analyzer (VNA) [2] as shown in figure $4 \& 5$ respectively 
International Journal of Science and Research (IJSR)

ISSN (Online): 2319-7064

Index Copernicus Value (2016): 79.57 | Impact Factor (2015): 6.391

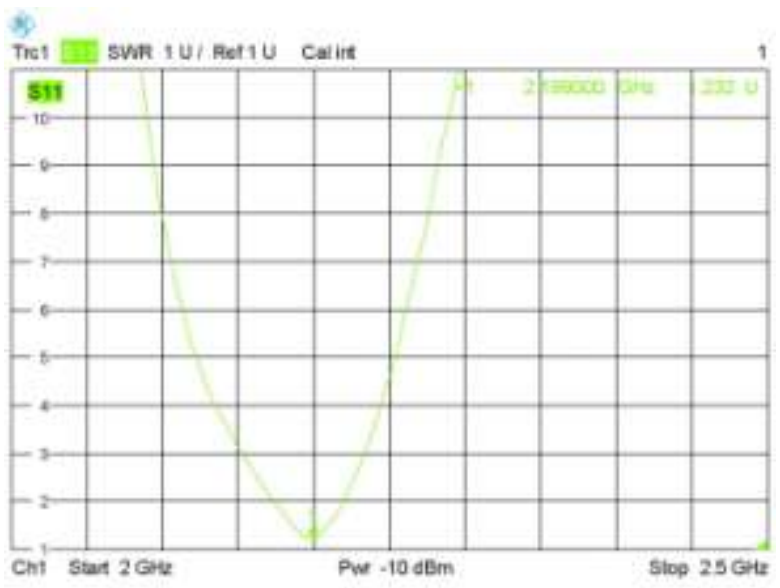

Figure 4: Fabricated results of VSWR

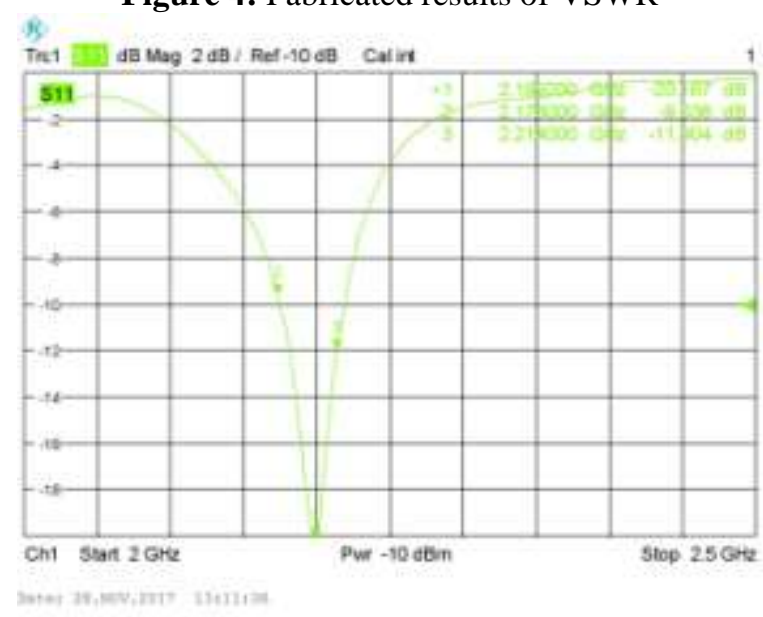

Figure 5: Fabricated results of Return Loss

Figure 5 gives the fabricated results of $\mathrm{E}$ shape antenna for VSWR and Return Loss respectively. In which VSWR is equals to 1.2 and return loss $-20.87 \mathrm{~dB}$. Table no. 2 shows the specification of proposed antenna.

Table2: Specification of Antenna

\begin{tabular}{|c|c|c|}
\hline \multirow{2}{*}{ Substrate } & Width & $42 \mathrm{~mm}$ \\
\cline { 2 - 3 } & Length & $46 \mathrm{~mm}$ \\
\cline { 2 - 3 } & Thickness & $1.5 \mathrm{~mm}$ \\
\hline \multirow{3}{*}{ Patch } & Width & $40 \mathrm{~mm}$ \\
\cline { 2 - 3 } & Length & $28.85 \mathrm{~mm}$ \\
\cline { 2 - 3 } & Thickness & $0.07 \mathrm{~mm}$ \\
\hline Dielectric constant & Substrate & 4.4 \\
\hline \multirow{2}{*}{ Material used } & Patch & Copper (cu) \\
\cline { 2 - 3 } & Substrate & Epoxy (FR4) \\
\hline
\end{tabular}

\section{Simulation and Result}

In order to evaluate the performance of the proposed $\mathrm{E}$ shape microstrip patch antenna, the antenna is simulated through the simulation tool HFSS V13. The analysis of the microstrip patch antenna for physical parameter has been done by varying one of them and keeping the others as constant.

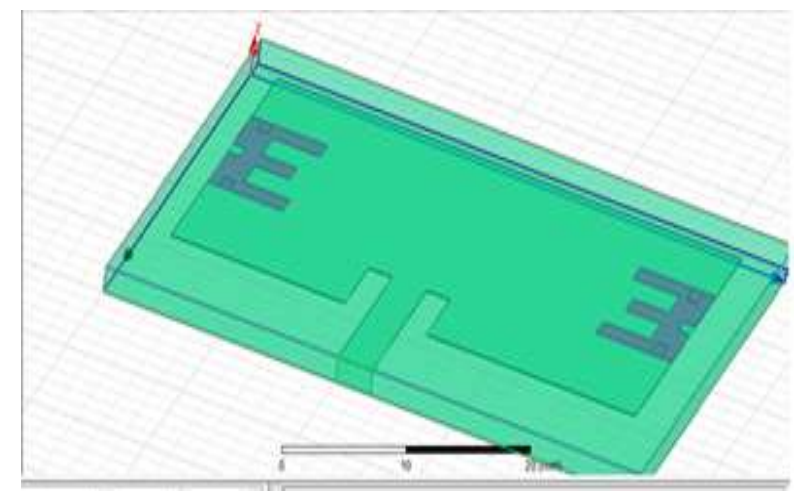

Figure 6: Simulated double E shape Antenna

After brief analysis of table given below it can easily determine that, the $\mathrm{E}$ shaped microstrip patch antenna with one middle slot having depth of patch $0.07 \mathrm{~mm}$ contains VSWR 1.06, Return Loss -53.9406. These values of VSWR and Return Loss are more optimized and improved over rest of all design.

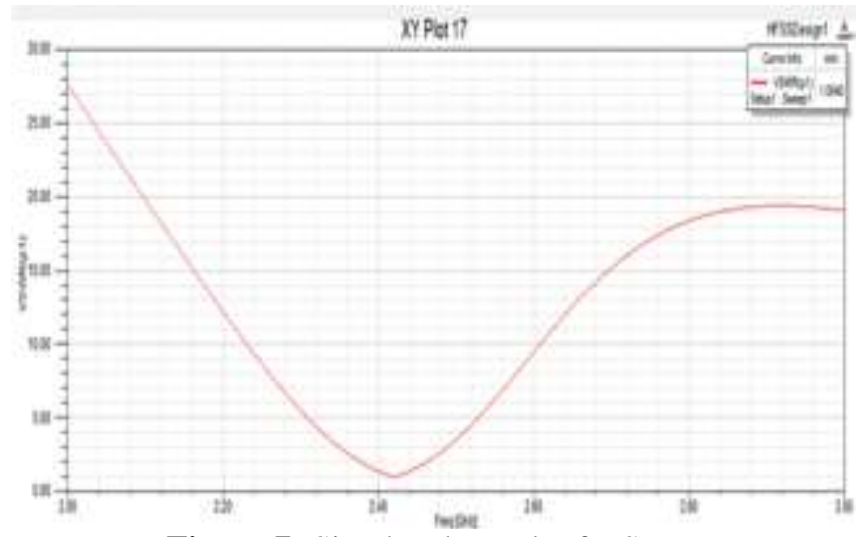

Figure 7: Simulated Result of VSWR

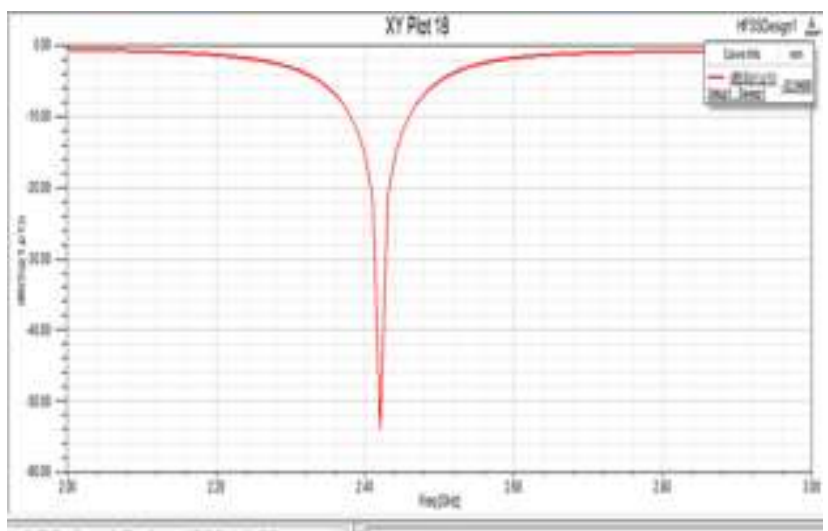

Figure 8: Simulated Result of Return Loss

Table 3: Comparative analysis of Microstrip patch Antenna

\begin{tabular}{|c|c|c|c|}
\hline $\begin{array}{c}\text { Sr. } \\
\text { No. }\end{array}$ & Shape of Patch & VSWR & Return Loss in dB \\
\hline 1 & E shaped with 2 slot & 1.06 & -29.067 \\
\hline 2 & E shaped with 1 slot at lower & 1.03 & -35.71 \\
\hline 3 & Plane E shaped & 1.02 & -36.51 \\
\hline 4 & E shaped with 3 slot & 1.01 & -42.71 \\
\hline 5 & Plane E shaped & 1.008 & -48.002 \\
\hline 6 & E shaped with 1 upper slot & 1.0076 & -48.0228 \\
\hline 7 & E shaped with 1 middle slot & 1.004 & -53.9406 \\
\hline
\end{tabular}

Volume 6 Issue 12, December 2017 


\section{Conclusion}

An E shaped Microstrip Patch Antenna is designed using mirror Effect technique and studied the various microstrip patch antenna briefly. The practicality of this system is examined using the ANSYS HFSS V13 software. This shows the performance of the system with $\mathrm{E}$ shaped having single middle slot is best as compared to rest of all at resonant frequency $2.4 \mathrm{~Hz}$.

\section{References}

[1] Divesh Mittal et. al., "Performance analysis of Microstrip Patch Antenna using CSRR and PSRR techniques for WLAN, WiMAX, Wi-Fi and IMT applications",IEEE WiSPNET 2016 conference,978-14673-9338-6, 2016.

[2] Kai-Fong Lee et. al. "Microstrip Patch Antennas Basic Characteristics and Some Recent Advances", Proceedings of the IEEE, Vol. 100, No. 7, July 2012.

[3] Shuchismita Pani et. al.,"Design and performance analysis of a dual band E-patch microstrip antenna in wireless communication",2015 International Conference on Soft Computing Techniques and Implementations (ICSCTI),978-1-4673-6792-9,2015.

[4] Behnam Jamali,Tony Cook, "Comparative Study of Microstrip Patch Antenna Feed Network", nternational Conference on Radar,ISBN 978-1-4673-5178-2, 04 November 2013.

[5] Chandan, B.S.Rai, "Design and Fabrication of EShaped Microstrip Patch Antenna for WLAN Application", International Conference on Computing for Sustainable Global Development (INDIACom), 978-9-3805-4421-2, 2016.

[6] Md. Maruf Ahamed, "Analysis And Design of Rectangular Microstrip Patch Antenna On Different Resonant Frequencies For Pervasive Wireless Communication",International Journal Of Scientific \& Technology Research Volume 1, Issue 5, ISSN 22778616. June 2012.

[7] Patil V. P., "Enhancement of Bandwidth of Rectangular Patch Antenna Using Two Square Slots Techniques", International Journal of Engineering Sciences \& Emerging Technologies, ISSN: 2231 - 6604, Volume 3, Issue 2, pp: 1-12, octomber 2012

[8] Alak Majumder, "Rectangular Micro strip Patch Antenna Using Coaxial Probe Feeding Technique to Operate in S-Band," International Journal of Engineering Trends and Technology,2013.

\section{Author Profile}

Miss. Snehal D. Tinganeis the student of P. G. Scholar student in Electronics and Tele Communication department from P R Pote College of Engineering \& Management, Amravati, Maharashtra, India.

Prof. P. N. Pusdekar is working as Assistant Professor in Electronics and Tele Communication department from P R Pote College of Engineering \& Management, Amravati, Maharashtra, India. 